\title{
Expression of connexin 32 and connexin 43 in acute myeloid leukemia and their roles in proliferation
}

\author{
SHA YI ${ }^{*}$, YAN CHEN ${ }^{*}$, LU WEN, LIJING YANG and GUOHUI CUI \\ Department of Hematology, Union Hospital, Tongji Medical College, \\ Huazhong University of Science and Technology, Wuhan, Hubei 430022, P.R. China
}

Received May 15, 2012; Accepted August 8, 2012

DOI: $10.3892 / \mathrm{ol} .2012 .884$

\begin{abstract}
Connexins (Cxs), a conserved family of transmembrane proteins, function in the organization of cell-cell communicatin via gap junctions in multicellular organisms. However, the role of Cxs in acute myeloid leukemia (AML) is poorly understood. In this study, we investigated the relationship between cell proliferation and expression of connexin 43 (Cx43) and connexin 32 (Cx32) mRNA and proteins in acute myeloid leukemia in vitro. Proliferation was observed using a growth curve and the rate of proliferation was detected by MTT assay in the acute myeloid leukemia cell lines OCI-AML3 and OCIM2. Cell cycle and cell proliferation index were assessed by flow cytometry analysis. The mRNA expression of the gap junction genes Cx43 and Cx32 was detected by RT-PCR. The expression of $\mathrm{Cx} 43$ and $\mathrm{Cx} 32$ proteins in the cell lines was analyzed by western blot analysis and immunofluorescence. The doubling time of OCI-AML3 and OCIM2 was $48 \mathrm{~h}$ and $36 \mathrm{~h}$, respectively. In OCIM2, the percentage of cells in the $\mathrm{S}$ phase fraction was $59.47 \pm 9.6 \%$, and the proliferation rate was $78.12 \pm 8.9 \%$; however, in OCI-AML3, the percentage of cells in the $\mathrm{S}$ phase was $24.95 \pm 5.8 \%$, and the proliferation rate was $35.21 \pm 6.7 \%$. At the mRNA level, both cell lines expressed $\mathrm{Cx} 43$ and $\mathrm{Cx} 32$, and there was no significant difference in the expression of $\mathrm{Cx} 43$ and $\mathrm{Cx} 32 \mathrm{mRNA}$ in the two cell lines. At the protein level, there was a significant difference in the expression of $\mathrm{Cx} 43$, but not of $\mathrm{Cx} 32$. The proliferation ability of OCIM2 was higher than OCI-AML3, and OCIM2 exhibited higher $\mathrm{Cx} 43$ western blot and fluorescence intensities compared with OCI-AML3. The results suggest that a higher expression of $\mathrm{Cx} 43$ in AML cells may play a significant role in the proliferation ability.
\end{abstract}

Correspondence to: Dr Guohui Cui, Department of Hematology, Union Hospital, Tongji Medical College, Huazhong University of Science and Technology, 1277 Jiefang Avenue, Wuhan, Hubei 430022, P.R. China

E-mail: ghcui@medmail.com.cn

*Contributed equally

Key words: connexins, acute myeloid leukemia, proliferation, expression

\section{Introduction}

Acute myeloid leukemia (AML) is the most common type of hematological malignancy characterized by key properties, including blocked differentiation, enhanced self-renewal and increased proliferation. Although there have been great developments in the understanding and treatment of AML, the mortality of AML is still high. Due to the difficulties in tolerance of treatment, the molecular mechanisms of uncontrolled proliferation of AML have been a major research project all over the world.

Gap junctions consist of arrays of intercellular channels composed of two hemichannels or connexons, one of which is formed by six protein subunits, termed connexins (Cxs). Cxs are a conserved family of transmembrane proteins which regulate the passage of biological molecules and allow the exchange of signaling molecules smaller than $1 \mathrm{kDa}$ between the cytoplasm of two neighboring cells, e.g. $\mathrm{Ca}^{2+}$, cyclic adenosine monophosphate (cAMP) and inositol triphosphate (IP3) (1-3). To date, at least 21 different human Cxs have been identified and they have been divided into two groups based on the primary amino acid sequence homology (3). It suggests that the dysregulation of $\mathrm{Cx}$ expression is related to uncontrolled proliferation, embryogenesis, tissue homeostasis and carcinogenesis (4). Recently, abnormal or defective gap junction communication in various solid tumors including liver, bladder, breast and prostate cancers was found (5), and accumulating research has also shown that restoring $\mathrm{Cx}$ gene expression and gap junction by gene therapy in Cx-deficient tumor cells could decrease tumor cell growth. However, despite much existing evidence, the exact contribution of the Cx channel family still remains controversial, as gap junction and cxs may furnish cell survival signals. The gap junction and cxs could exert their effect on promoting cancer cell proliferation $(6,7)$. Each $\mathrm{Cx}$ shows tissue cell-specific expression, and Cx43 is the major component of hematopoietic tissue (8-11). Cx32 was also found to be important in bone marrow stromal cells $(12,13)$. Until now, there have been few studies focusing on the expression of the gap junction genes in the AML cell lines, and little is known regarding the correlation between cell proliferation and Cxs. In this study, the AML cell lines OCI-AML3 and OCIM2 were employed to investigate the expression of $\mathrm{Cx} 32$ and $\mathrm{Cx} 43$ in AML and their role in proliferation. 


\section{Materials and methods}

Cell culture. The OCI-AML3 and OCIM2 were kindly provided by M.D. Minden (Ontario Cancer Institute, Toronto, ON, Canada). OCI/AML3 (FAB M4) was established from a patient with AML, and OCIM2 (FAB M6) from a patient with erythroleukemia. The cells were grown in RPMI-1640 supplemented $10 \%$ fetal bovine serum (FCS). Cultures were maintained in a humidified atmosphere with $5 \% \mathrm{CO}_{2}$ at $37^{\circ} \mathrm{C}$.

Chemicals and antibodies. Thiazolyl blue tetrazolium bromide (MTT), dimethysulfoxide (DMSO), prodidum iodide (PI) and Hoechst 33258 were bought from Sigma (Sigma-Aldrich, St. Louis, MO, USA). Polyclonal rabbit antibody against $\mathrm{Cx} 43$ and Cx32 were purchased from Cell Signaling Technology, Inc. (Danvers, MA, USA) and PTG (Chicago, IL, USA). $\gamma$-tubulin was bought from Jackson ImmunoResearch (Jackson, WY, USA).

Cell growth curve. The OCI-AML3 and OCIM2 cells were seeded in 24 -well plates $\left(2 \times 10^{4}\right.$ per well), cultured in a humidified atmosphere with $5 \% \mathrm{CO}_{2}$ at $37^{\circ} \mathrm{C}$. The cells were harvested and counted on days 1-4, three wells each time and three times each well, to obtain an average to draw the growth curve.

Cell proliferation assay. The proliferative rate of OCI-AML3 and OCIM2 was determined by MTT assay following the method of Mosmann (14). The OCI-AML3 and OCIM2 cells $\left(1 \times 10^{4}\right.$ per well) were cultured for 24,48 and $72 \mathrm{~h}$ in 96-well plates. Thereafter, $20 \mu 1$ MTT solution was added to each well. After continued incubation for $4 \mathrm{~h}$, the supernatant was discarded and $150 \mu \mathrm{l}$ DMSO was added. Once the blue crystals were dissolved, the optical density (OD) was measured at $490 \mathrm{~nm}$ with background substraction of $630 \mathrm{~nm}$ using a plate microreader (Tecan Spectra, Wetzlar, Germany). The experiments were performed in triplicate. The proliferation rate was determined using the following formula: Cell proliferation (\%) $=\mathrm{OD}$ of the experimental samples / OD of the control x $100 \%$ $(\mathrm{n}=3$, mean $\pm \mathrm{SD})$.

Cell cycle analysis. The OCI-AML3 and OCIM2 $\left(1 \times 10^{6}\right.$ cells $)$ were harvested. After being washed, the cells were fixed with $75 \%$ ice-cold ethanol and maintained overnight at $4^{\circ} \mathrm{C}$. The cells were collected and resuspended in PBS containing $40 \mu \mathrm{g} / \mathrm{ml}$ PI, $0.1 \mathrm{mg} / \mathrm{ml}$ RNase, and 5\% Triton X-100, and then incubated at $37^{\circ} \mathrm{C}$ for $30 \mathrm{~min}$. The cells were evaluated by flow cytometry (FCM) using FACS (BD, San Diego, CA, USA). At least 10,000 counts were made for each sample. The percentage distribution in the cell cycle phases was analyzed using CellQuest. The proliferation index (PI) was determined using the following formula: $\mathrm{PI}=(\mathrm{S}+\mathrm{G} 2 / \mathrm{M}) /(\mathrm{G} 0 / \mathrm{G} 1+\mathrm{S}+\mathrm{G} 2 / \mathrm{M})$.

Semi-quantitative reverse transcription-PCR (RT-PCR). Total RNA was extracted from OCI-AML3 and OCIM2 cells using TRIzol reagent (Invitrogen, Carlsbad, CA, USA). Following quantification by spectrophotometry, the first-strand cDNA was synthesized from $2 \mu \mathrm{g}$ of total RNA with the RevertAid First-Strand cDNA Sythesis kit. Cx43: forward 5'-TCGCCTATGTCTCCTCCTGG-3', reverse 5'-GCTGGCTCTGCTTGAAGGTC-3', with a PCR product
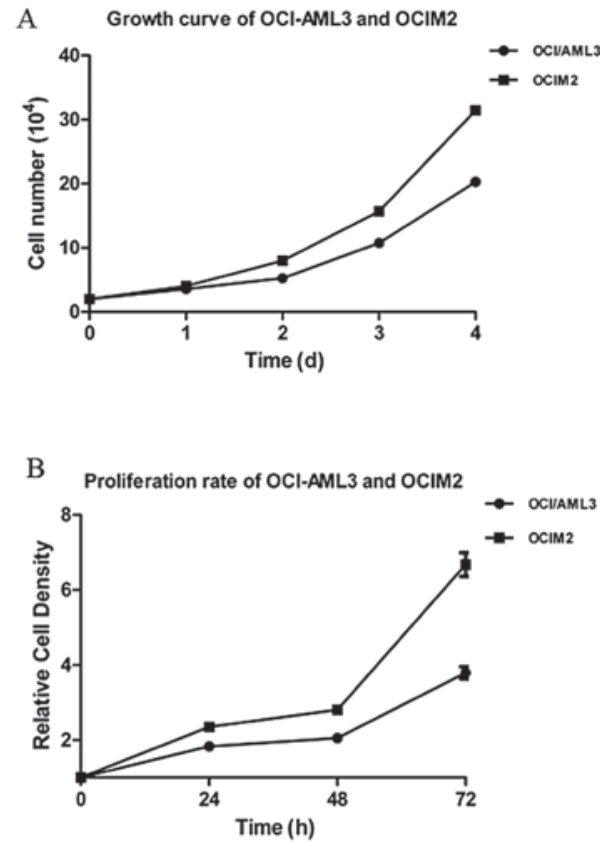

Figure 1. Assessment of proliferation rate of OCI-AML3 and OCIM2. (A) The OCI-AML3 and OCIM2 cells were seeded and cultured for 1, 2, 3 and 4 days. The cell number was counted each day. (B) The cells were seeded and cultured for $24 \mathrm{~h}, 48 \mathrm{~h}$ and $72 \mathrm{~h}$. Viable cells were detected by MTT assay and the proliferation rate was calculated. The data shown is the mean $\pm \mathrm{SD}$ from three independent experiments.

of $270 \mathrm{bp}$; Cx32: forward 5'-AAATGCTACGGCTTGA GGGC-3', reverse 5'-CGGAACACCACGCTGATGAC-3', which can amplify a 115 bp fragment; $\beta$-actin: forward 5'-GCGGGA AATCGTGCGTGACATTA-3', reverse 5'-GACTCGTCATACTCCTGCTTGCTGAT-3', with an expected PCR product of $480 \mathrm{bp}$. The products were electrophoresesed on $2 \%$ agarose gel and the ratio between the target gene and $\beta$-actin gene band density was used for quantitative evaluation.

Western blot analysis. For preparation of total cell lysates, cells were collected and lysed in lysis buffer (50 mM HEPES, $150 \mathrm{mM} \mathrm{NaCl}, 1 \%$ Triton X-100, 5 mM EGTA, $50 \mathrm{mM}$ glycerophosphate, $20 \mathrm{mM} \mathrm{NaF}, 1 \mathrm{mM} \mathrm{Na}_{3} \mathrm{VO}_{4}, 2 \mathrm{mM}$ phenylmet-hyl sulfonyl fluoride, $10 \mu \mathrm{g} / \mathrm{ml}$ leupeptin and $10 \mu \mathrm{g} / \mathrm{ml}$ aprotinin) by incubating on ice for $30 \mathrm{~min}$. Lysates were then centrifuged at $12,000 \mathrm{x}$ g for $15 \mathrm{~min}$ at $4^{\circ} \mathrm{C}$. The supernatant was collected and the total protein concentrations were determined using the BCA assay by spectrophotometer (Biotech Instruments, NY, USA). Samples were separated on 10\% SDS-PAGE and transferred onto nitrocellulose membranes. After blocking with $5 \%$ non-fat dry milk in blocking buffer $(25 \mathrm{mM}$ Tris, $\mathrm{pH} 7.5,150 \mathrm{mM} \mathrm{NaCl}$, and $0.1 \%$ Tween-20), the membranes were incubated with primary antibodies at $4^{\circ} \mathrm{C}$ overnight. The membranes were then incubated with appropriate peroxidaseconjugated secondary antibodies, and the protein expression was detected by ECL substrate solution (Thermo Scientific, Rockford, IL, USA). Densitometric analysis was performed using Quantity One software.

Fluorescent immunostaining. OCI-AML3 and OCIM2 cells were collected and washed with PBS and then fixed with 


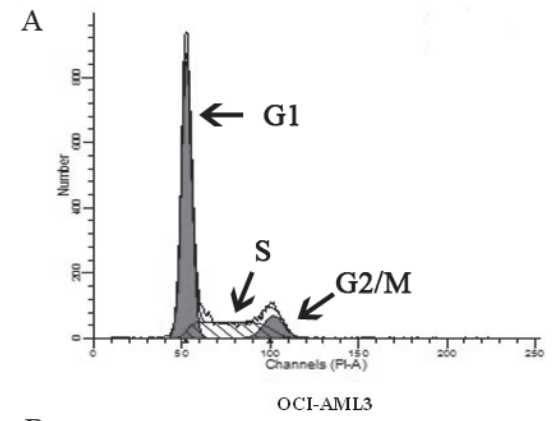

B

The percentage distribution of the cell cycle phases

\begin{tabular}{lcccc}
\hline Group & G1 (\%) & S (\%) & G2/M (\%) & PI \\
\hline OCI-AIII3 & $64.79 \pm 4.3$ & $24.96 \pm 5.8$ & $10.26 \pm 8.7$ & $35.21 \pm 6.7$ \\
OCIN2 & $21.52 \pm 7.3$ & $59.47 \pm 9.6$ & $19.01 \pm 6.9$ & $78.12 \pm 8.9$ \\
\hline
\end{tabular}

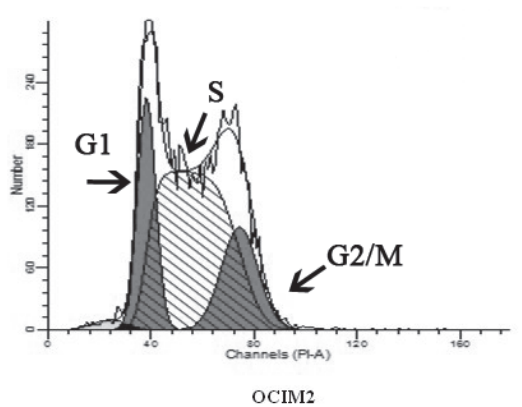

C

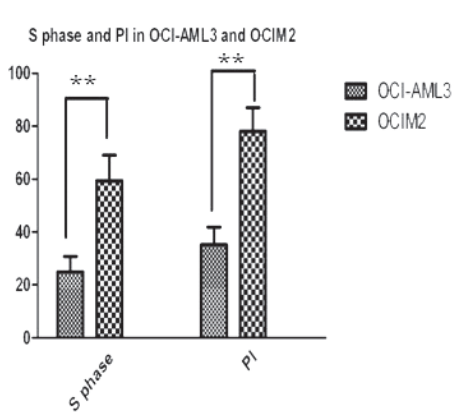

Figure 2. Assessment of cell cycle phase and proliferation index (PI) of OCI-AML3 and OCIM2. (A) The OCI-AML3 and OCIM2 cells were harvested and evaluated by flow cytometry using FACS. (B) The percentage distribution in the cell cycle phases was analyzed using CellQuest. The PI was determined using the following formula: $\mathrm{PI}=(\mathrm{S}+\mathrm{G} 2 / \mathrm{M}) /(\mathrm{G} 0 / \mathrm{G} 1+\mathrm{S}+\mathrm{G} 2 / \mathrm{M})$. (C) $\mathrm{S}$ phase and PI are shown in histogram. Statistical significance was determined by the Student's t-test. The data shown is the mean $\pm \mathrm{SD}$ from three independent experiments. ${ }^{* *} \mathrm{P}<0.01$.

$40 \mathrm{mg} / \mathrm{l}$ paraformaldehyde for $10 \mathrm{~min}$ before deposition on polylysine-coated coverslips. After washing, samples were blocked with $10 \%$ goat serum albumin for $30 \mathrm{~min}$. The cells were reacted overnight at $4^{\circ} \mathrm{C}$ with a drop of 1:100 diluted Cx43 antibody, then washed and incubated with a drop of 1:500 diluted Cy3-labeled goat anti-rabbit IgG (Sigma, USA) for $1 \mathrm{~h}$. After that, cells were stained with Hoechst 33258 for $30 \mathrm{~min}$ at $37^{\circ} \mathrm{C}$. Finally, the slides were mounted with $50 \%$ glycerol and observed by Olympus BH-2 fluorescence microscope (Tokyo, Japan).

Statistical analysis. The statistical significance of difference between control and treatment groups was determined by the Student's t-test. Values are shown as the mean $\pm \mathrm{SD}$, and $\mathrm{P}<0.05$ was considered to indicate a statistically significant difference.

\section{Results}

Growth curve and proliferation rate in $A M L$ cell lines OCI-AML3 and OCIM2. The OCI-AML3 and OCIM2 cells were seeded and cultured for 1-4 days, and cells were harvested and counted each day. According to the growth curve, as shown in Fig. 1A, the doubling time of OCI-AML3 and OCIM2 was 48 and 36 h respectively, and OCIM2 grew faster than OCI-AML3. To further confirm the proliferation rate of OCI-AML3 and OCIM2, the cells were seeded and cultured for 24, 48 and $72 \mathrm{~h}$ and detected by MTT. As shown in Fig. 2, the proliferation rate of OCIM2 was nearly twice that of OCI-AML3.

Cell cycle distribution and PI in AML cell lines OCI-AML3 and OCIM2. As shown in Fig. 2A, the cell cycle distribution of AML cell lines OCI-AML3 and OCIM2 was determined by FCM. As shown in Fig. 2B, the percentage of OCI-AML3 cells in the $\mathrm{S}$ phase fraction was $24.95 \pm 5.8 \%$; however, the percentage of OCIM2 cells was much higher, at OCI-AML3, at $59.47 \pm 9.6 \%$. At the same time, the PI of OCI-AML3 and OCIM2 was calculated to further confirm the role of the cell cycle in the proliferation rate of these two cell lines. As shown in Fig. 2B, that of OCIM2 was $78.12 \pm 8.9 \%$, however, the PI of OCI-AML3 was only $35.21 \pm 6.7 \%$. There were significant differences in $\mathrm{S}$ phase distribution and PI between OCI-AML3 and OCIM2, as shown in Fig. 2C $(\mathrm{P}<0.01)$.

Expression of Cx32, Cx43 mRNA and proteins in AML cell lines OCI-AML3 and OCIM2. To investigate whether there was a difference in the expression of Cxs in AML cell lines OCI-AML3 and OCIM2, the expression of Cx32, and Cx43 mRNA in OCI-AML3 and OCIM2 was detected by RT-PCR. The protein levels of $\mathrm{Cx} 32$ and $\mathrm{Cx} 43$ were determined by western blot assay and immunofluorescence. As shown in Fig. 3C and D, the RT-PCR assay showed that the expression of Cx43 and Cx32 mRNA in these two cell lines was not significantly different $(\mathrm{P}>0.05)$. In contrast, a clear difference was noted between OCI-AML3 and in OCIM2 in the expression of Cx43 protein. As shown in Fig. 3A and B, the protein level of Cx43 in OCIM2 was notably higher than that of OCI-AML3 $(\mathrm{P}<0.01)$.

Cx43 proteins appeared as a collection of red spots intracytoplasmically and in certain parts of the plasma membrane, as shown in Fig. 4A. The immunofluorescence assay showed that the fluorescence intensity of $\mathrm{Cx} 43$ protein in OCIM2 was higher than that in OCI-AML3. OCIM2 cells showed both stronger western blot and fluorescence intensity. These results suggested that the expression of Cx43 in OCIM2 was much 


$$
\begin{gathered}
{ }_{\mathrm{Cx} 43} \\
\mathrm{Cx} 32 \\
\gamma \text {-tubulin }
\end{gathered}
$$

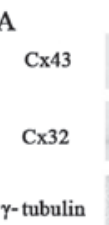

B
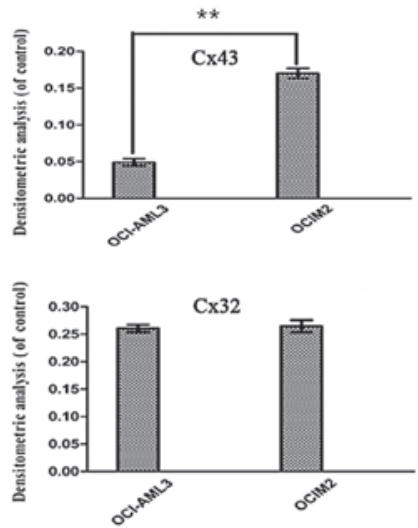

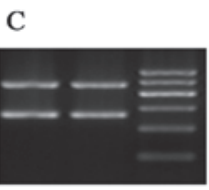

OCI-AML3 OCIM2

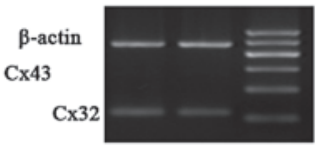

OCI-AML3 OCIM2

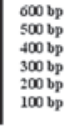

$5006 \mathrm{pp}$
$4000 \mathrm{pp}$
$300 \mathrm{pp}$
$200 \mathrm{bp}$
$1006 \mathrm{~b}$

D
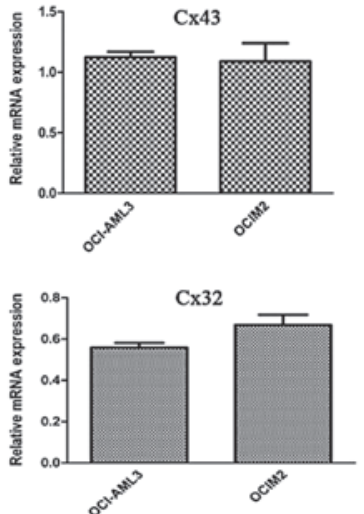

Figure 3. The expression of Cx43 and Cx32 mRNA and protein in OCI-AML3 and OCIM2. (A) The OCI-AML3 and OCIM2 cells were harvested and the protein level of $\mathrm{Cx} 43$ and $\mathrm{Cx} 32$ was determined by western blot assay. (B) The values for $\mathrm{Cx} 43$ and $\mathrm{Cx} 32$ were corrected relative to $\gamma$-tubulin and are shown in the histogram. (C) The OCI-AML3 and OCIM2 cells were harvested and the mRNA levels of Cx43 and Cx32 were determined by RT-PCR. $\beta$-actin was used as an equal loading control. (D) The bands were quantified by densitometric analysis and are shown in the histogram. Statistical significance was determined by the Student's t-test. The data is represented as the mean $\pm \mathrm{SD}$ from three independent experiments. ${ }^{* *} \mathrm{P}<0.01$.
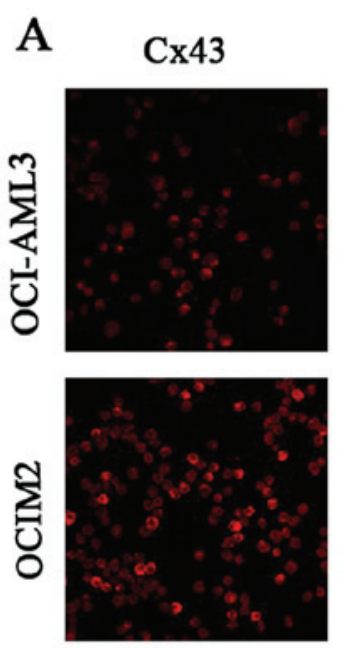

Merge
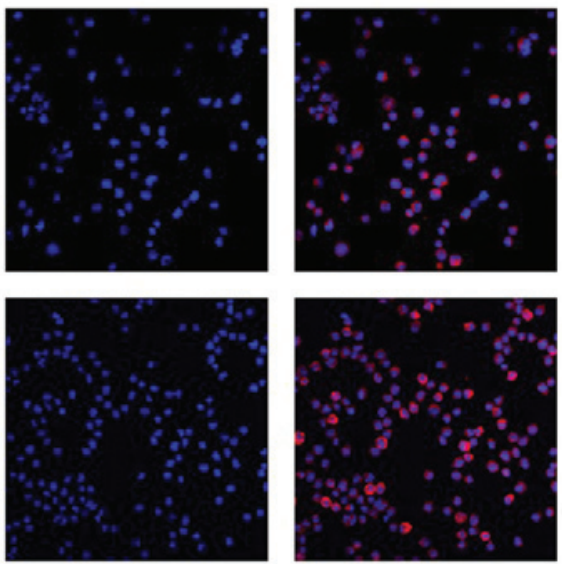

Hoechst
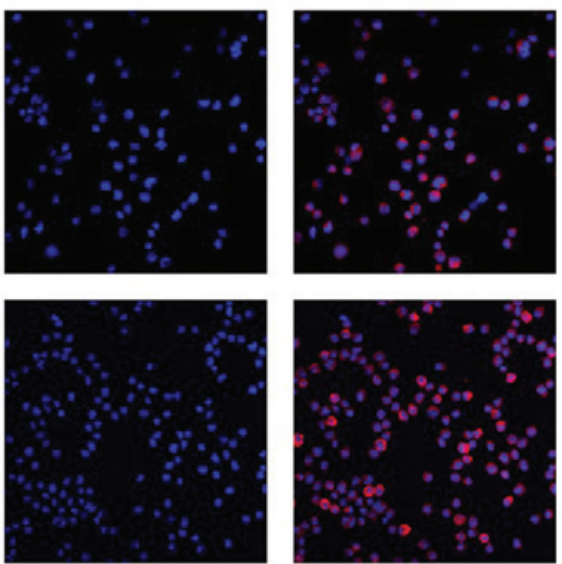

B

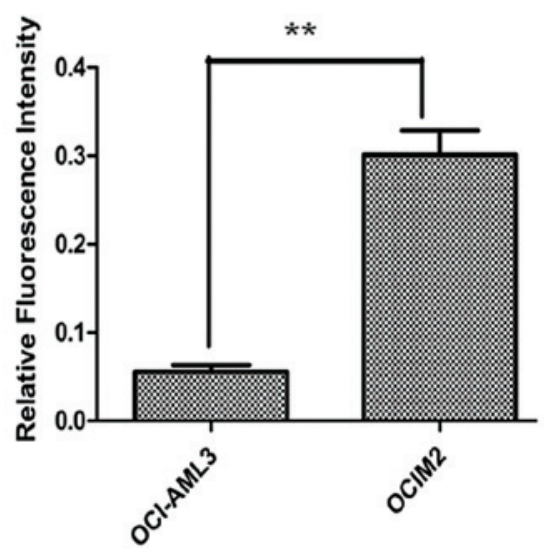

Figure 4. (A) The expression of Cx43 in OCI-AML3 and OCIM2 detected by immunofluorescence. The representative images are shown. (B) The intensity of $\mathrm{Cx} 43$ was quantitated by densitometric analysis and is shown in the histogram. Statistical significance was determined by the Student's t-test. The data is represented as the mean $\pm \mathrm{SD}$ from three independent experiments. ${ }^{* *} \mathrm{P}<0.01$.

higher than OCI-AML3 at the protein level, but there was no difference at the mRNA level.

\section{Discussion}

Deviation of physiological cell cycling, as a consequence of homeostatic imbalance, may lead to uncontrolled cell proliferation activity (15-17). The $\mathrm{S}$ phase (synthesis phase) is the part of the cell cycle in which DNA is replicated, occurring between the G1 and G2 phase, which is a reliable marker to indicate how fast a tumor is growing. In clinical practice, the $S$ phase fraction could be used as an independent prognostic factor in node-negative invasive breast carcinoma (18). The proliferative index $(\mathrm{PI})$ is a measure of the number of proliferated cells in a tumor, which is also an indicator of the cell proliferation rate. Our results revealed that OCIM2 grew much faster than OCI-AML3 and that the proliferation ability of OCIM2 was much stronger than that of OCI-AML3. In addition, the results showed that the S phase percentage and PI of OCIM2 was higher than OCI-AML3. Since acute erythroleukemia is an uncommon subtype of AML associated with a very poor prognosis compared to other subtypes, such as OCI-AML3, these results support the use of the $\mathrm{S}$ phase fraction as a parameter to predict the proliferation rate in AML cells. 
It is well known that gap junctions, a group of specialized cell-to-cell junctions composed of Cx proteins (19-21), are critical gatekeepers of cell proliferation, controlling the intercellular exchange of essential growth regulators (22). The role of Cxs in leukemogenesis and leukemic cell functions are not well defined. Previous studies have clearly shown that soluble mediators alter AML cell proliferation and apoptosis both when the leukemic cells are cultured alone and when co-cultured with fibroblasts, endothelial cells and osteoblasts (23). Furthermore, direct cell-cell interactions between AML cells also alter AML cell function. Even though the function of $\mathrm{Cx}$ building blocks affects the regulation of several cellular functions, including growth and apoptosis of normal and malignant cells, and also appears to be important for chemosensitivity, little is known about their role in leukemic cell functions. Certain reports demonstrate that overexpression or genetic mutation of $\mathrm{Cx}$ could induce tumor cell growth and inhibit G1/S cell cycle arrest $(12,24,25)$. In contrast, several studies have demonstrated that the presence of Cxs is indispensable for the enrollment of cell proliferation (26-29). Our research demonstrated a lower expression of $\mathrm{Cx} 43$ in OCI-AML3 than OCIM2, but RT-PCR results revealed no decrease of Cx43 mRNA in these two cell lines. It is of note, however, that the same level of Cx32 mRNA and proteins was detected in OCIM2 and OCI-AML3 cell lines. It appears that $\mathrm{Cx} 43$ gene transcription was not responsible for the aberrant expression of $\mathrm{Cx} 43$ proteins. Although there was no difference in the expression of $\mathrm{Cx} 32$ both at the transcriptional and protein level, we found that there was a significant difference in the expression of $\mathrm{Cx} 43$ at the protein level. Therefore, the results of the present study indicate that $\mathrm{Cx} 43$ could be considered as a potential tumor promoter which exerts its effect by promoting the exchange of growth factors or facilitating proliferation by itself as a pro-survival signal, and may also have a correlation with malignant AML cell proliferation. Further investigation is required to understand the precise mechanism in which intercellular communication participates in neoplastic growth in the hematopoietic process.

\section{Acknowledgements}

This study was supported by grants from the National Natural Science Foundation of China (no. 81070429).

\section{Reference}

1. Oyamada M, Oyamada Y and Takamatsu T: Regulation of connexin expression. Biochim Biophys Acta 1719: 6-23, 2005.

2. Konopleva M, Konoplev S, Hu W, Zaritskey AY, Afanasiev BV and Andreeff M: Stromal cells prevent apoptosis of AML cells by up-regulation of anti-apoptotic proteins. Leukemia 16 1713-1724, 2002.

3. Laird DW: Life cycle of connexins in health and disease. Biochem J 394: 527-543, 2006.

4. Cronier L, Crespin S, Strale PO, Defamie N and Mesnil M: Gap junctions and cancer: new functions for an old story. Antioxid Redox Signal 11: 323-338, 2009.

5. Mesnil M, Crespin S, Avanzo JL and Zaidan-Dagli ML: Defective gap junctional intercellular communication in the carcinogenic process. Biochim Biophys Acta 1719: 125-145, 2005.

6. Giardina SF, Mikami M, Goubaeva F and Yang J: Connexin 43 confers resistance to hydrogen peroxide-mediated apoptosis. Biochem Biophys Res Commun 362: 747-752, 2007.
7. Freidin M, Asche S, Bargiello TA, Bennett MV and Abrams CK: Connexin 32 increases the proliferative response of Schwann cells to neuregulin-1 (Nrg1). Proc Natl Acad Sci USA 106: 3567-3572, 2009

8. Li X, Xu YB, Wang Q, et al: Leukemogenic AML1-ETO fusion protein upregulates expression of connexin 43: the role in AML 1-ETO-induced growth arrest in leukemic cells. J Cell Physiol 208: 594-601, 2006.

9. Liu Y, Zhang X, Li ZJ and Chen XH: Up-regulation of Cx43 expression and GJIC function in acute leukemia bone marrow stromal cells post-chemotherapy. Leuk Res 34: 631-640, 2010.

10. Liu Y, Zhang X, Si YJ, Gao L and Chen XH: [Connexin 43 expression and interacellular communicating function in acute leukemia bone marrow stroma cells]. Zhongguo Shi Yan Xue Ye Xue Za Zhi 15: 679-682, 2007.

11. Krenacs $\mathrm{T}$ and Rosendaal M: Connexin43 gap junctions in normal, regenerating, and cultured mouse bone marrow and in human leukemias: their possible involvement in blood formation. Am J Pathol 152: 993-1004, 1998.

12. Sato H, Hagiwara H, Ohde Y, Senba H, Virgona N and Yano T: Regulation of renal cell carcinoma cell proliferation, invasion and metastasis by connexin 32 gene. J Membr Biol 216: 17-21, 2007.

13. Hirabayashi Y, Yoon BI, Tsuboi I, et al: Protective role of connexin 32 in steady-state hematopoiesis, regeneration state, and leukemogenesis. Exp Biol Med (Maywood) 232: 700-712, 2007.

14. Spinner DM: MTT growth assays in ovarian cancer. Methods Mol Med 39: 175-177, 2001

15. Malumbres $\mathrm{M}$ and Barbacid M: Cell cycle, CDKs and cancer: a changing paradigm. Nat Rev Cancer 9: 153-166, 2009.

16. Suryadinata R, Sadowski M and Sarcevic B: Control of cell cycle progression by phosphorylation of cyclin-dependent kinase (CDK) substrates. Biosci Rep 30: 243-255, 2010.

17. van den Heuvel S: Cell-cycle regulation. WormBook 1-16, 2005.

18. Moureau-Zabotto L, Bouchet C, Cesari D, et al: Combined flow cytometry determination of S-phase fraction and DNA ploidy is an independent prognostic factor in node-negative invasive breast carcinoma: analysis of a series of 271 patients with stage I and II breast cancer. Breast Cancer Res Treat 91: 61-71, 2005.

19. Vinken M, Vanhaecke T, Papeleu P, Snykers S, Henkens T and Rogiers V: Connexins and their channels in cell growth and cell death. Cell Signal 18: 592-600, 2006.

20. Vinken M, Henkens T, De Rop E, Fraczek J, Vanhaecke T and Rogiers V: Biology and pathobiology of gap junctional channels in hepatocytes. Hepatology 47: 1077-1088, 2008.

21. Vinken M, De Rop E, Decrock E, et al: Epigenetic regulation of gap junctional intercellular communication: more than a way to keep cells quiet? Biochim Biophys Acta 1795: 53-61, 2009.

22. Decrock E, Vinken M, De Vuyst E, et al: Connexin-related signaling in cell death: to live or let die? Cell Death Differ 16: 524-536, 2009.

23. Hatfield K, Ryningen A, Corbascio $M$ and Bruserud O: Microvascular endothelial cells increase proliferation and inhibit apoptosis of native human acute myelogenous leukemia blasts. Int J Cancer 119: 2313-2321, 2006.

24. Roger C, Mograbi B, Chevallier D, et al: Disrupted traffic of connexin 43 in human testicular seminoma cells: overexpression of Cx43 induces membrane location and cell proliferation decrease. J Pathol 202: 241-246, 2004.

25. Sato H, Fukumoto K, Hada S, et al: Enhancing effect of connexin 32 gene on vinorelbine-induced cytotoxicity in A549 lung adenocarcinoma cells. Cancer Chemother Pharmacol 60: 449-457, 2007.

26. Chadjichristos CE, Matter CM, Roth I, et al: Reduced connexin43 expression limits neointima formation after balloon distension injury in hypercholesterolemic mice. Circulation 113: 2835-2843, 2006.

27. Ozawa H, Mutai H, Matsunaga T, et al: Promoted cell proliferation by connexin 30 gene transfection to head-and-neck cancer cell line. Anticancer Res 29: 1981-1985, 2009.

28. Wang HH, Kung CI, Tseng YY, et al: Activation of endothelial cells to pathological status by down-regulation of connexin43. Cardiovasc Res 79: 509-518, 2008.

29. Liu X, Furuya T, Li D, et al: Connexin 26 expression correlates with less aggressive phenotype of intestinal type-gastric carcinomas. Int J Mol Med 25: 709-716, 2010. 